\title{
Predicting extreme loads effects on wind turbines considering uncertainty in airfoil data
}

\author{
Abdallah, Imad; Natarajan, Anand; Sørensen, John Dalsgaard
}

Published in:

Safety, Reliability, Risk and Life-Cycle Performance of Structures and Infrastructures - Proceedings of 11th International Conference on Structural Safety and Reliability

Publication date:

2013

Link back to DTU Orbit

Citation (APA):

Abdallah, I., Natarajan, A., \& Sørensen, J. D. (2013). Predicting extreme loads effects on wind turbines considering uncertainty in airfoil data. In Safety, Reliability, Risk and Life-Cycle Performance of Structures and Infrastructures - Proceedings of 11th International Conference on Structural Safety and Reliability (pp. 215-222). Taylor \& Francis.

\section{General rights}

Copyright and moral rights for the publications made accessible in the public portal are retained by the authors and/or other copyright owners and it is a condition of accessing publications that users recognise and abide by the legal requirements associated with these rights.

- Users may download and print one copy of any publication from the public portal for the purpose of private study or research.

- You may not further distribute the material or use it for any profit-making activity or commercial gain

- You may freely distribute the URL identifying the publication in the public portal 


\title{
Predicting extreme loads effects on wind turbines considering uncertainty in airfoil data
}

\author{
Imad Abdallah \\ WindNordic A/S, Incuba Science Park, Aabogade 15, DK 8200 Aarhus, Denmark; Technical University of Denmark, Department \\ of Wind Energy, Risø Campus, DK-4000 Roskilde, Denmark
}

Anand Natarajan

Technical University of Denmark, Department of Wind Energy, Risø Campus, DK-4000 Roskilde, Denmark

John Dalsgaard Sørensen

Aalborg University, Department of Civil Engineering, Sohngårdsholmsvej 57, DK-9000 Aalborg, Denmark; Technical University of Denmark, Department of Wind Energy, Risø Campus, DK-4000 Roskilde, Denmark

\begin{abstract}
The sources contributing to uncertainty in a wind turbine blade static airfoil data include wind tunnel testing, CFD calculations, 3D rotational corrections based on CFD or empirical models, surface roughness corrections, Reynolds number corrections, expansion to the full 360-degree angle of attack range, validation by full scale measurements, and geometric distortions of the blade during manufacturing and under loading. In this paper a stochastic model of the static airfoil data is proposed to supplement the prediction of extreme loads effects for large wind turbines. It is shown that the uncertainty in airfoil data can have a significant impact on the prediction of extreme loads effects depending on the component, and the correlation along the span of the blade.
\end{abstract}

\section{INTRODUCTION}

Considerable effort and capital is invested in predicting the static aerodynamic lift and drag polar curves of airfoils as accurately as possible, which are then used by the designer as input to aero-servoelastic software to predict extreme and fatigue loads in addition to stability margins in operation and stand still. Airfoil characteristics are almost exclusively derived in wind tunnels. However, an airfoil section in the field operates in 3-dimensional, unsteady and turbulent inflow under the influence of a control system, which a 2D static wind tunnel test does not take into account nor fully replicate. The various sources contributing to uncertainty in airfoil data have been studied by McCroskey (1987), Simms et al. (2001), Loeven et al. (2008), Witteveen et al (2009), Bak et al. (2010) and Petrone et al. (2011). In this paper a stochastic model of the airfoil lift and drag coefficients is proposed by the quantification of uncertainties based on field and wind tunnel data, numerical calculations and engineering judgment. The stochastic model is developed by (1) replicating the physical variations in airfoil data by parameterizing the lift and drag polar curves, (2) allowing selected points on the lift and drag curves to be distributed randomly around the measured values and (3) simulating their impact on extreme loads effects using a Monte Carlo scheme with varying degree of correlation along the blade length. The proposed stochastic model replicates physical, model, statistical and measurement uncertainties of airfoil data and it can be used to model extreme loads effects in both semi-probabilistic design and in relia- bility analysis of wind turbines. A modern multimegawatt offshore wind turbine is considered in the calculations of the extreme loads effects (nominal power $>5 \mathrm{MW}$ and rotor diameter $>130 \mathrm{~m}$ ).

\subsection{Nomenclature}

$\begin{array}{ll}\text { Variable } & \text { Definition } \\ \mathrm{C}_{\mathrm{L}, \max } & \text { Max lift coefficient } \\ \text { AoA }_{\max } & \text { Angle of attack where } \mathrm{C}_{\mathrm{L}, \text { max }} \text { occurs } \\ \mathrm{C}_{\mathrm{L}, \mathrm{TES}} & \text { Lift coefficient where trailing edge separation starts } \\ \text { AoA }_{\mathrm{TES}} & \text { Angle of attack corresponding to } \mathrm{C}_{\mathrm{L}, \mathrm{TES}} \\ \mathrm{C}_{\mathrm{L}, \mathrm{SR}} & \text { Lift coefficient where stall recovery starts } \\ \text { AoA } & \text { Angle of attack where stall recovery starts } \\ \mathrm{C}_{\mathrm{L}, 90} & \text { Lift coefficient at } 90 \text { degree angle of attack } \\ \mathrm{C}_{\mathrm{D}, 90} & \text { Drag coefficient at } 90 \text { degree angle of attack } \\ \mathrm{TES} & \text { Trailing Edge Separation } \\ \mathrm{COV} & \text { Coefficient of Variation } \\ \mathrm{Re} & \text { Reynolds number }\end{array}$

\section{STOCHASTIC MODEL OF AERODYNAMIC LIFT AND DRAG POLAR CURVES}

\subsection{Aerodynamic theory}

The rate of change of lift coefficient with angle of attack, $\mathrm{dC}_{\mathrm{L}} / \mathrm{d} \alpha$, can be inferred from thin airfoil theory to be $2 \pi$ per radian change of angle of attack and is within $+/-10 \%$ of $2 \pi / \mathrm{rad}$ when taking the effects of thickness and viscosity into account. Deviation from the linear slope is seen as the start of the progressive movement of the turbulent flow separation point from the trailing edge (TE) towards the leading edge. As the separation point moves upstream along 
the suction side the $C_{L}$ progresses to the point of maximum lift as depicted in Figure 1. The angle of attack at maximum lift is termed the static stall angle of attack (AoA). The drag coefficient is constant or slightly increasing. Beyond the stall angle of attack, the lift coefficient starts to decrease; the stalled region on the suction side of the airfoil continues to grow as the separation point continues its progression upstream to the airfoil leading edge. When leading edge separation (also called deep stall) is reached, increasing AoA further often results in a neutral or even slightly increasing lift, but with drag steadily increasing at a much faster rate until a 90 degree AoA. In the parameterized lift and drag curves used in the investigations in this paper, the linear slope, the point of TE flow separation, the point of maximum lift, the point of deep stall and the point of maximum drag are varied according to a stochastic model.

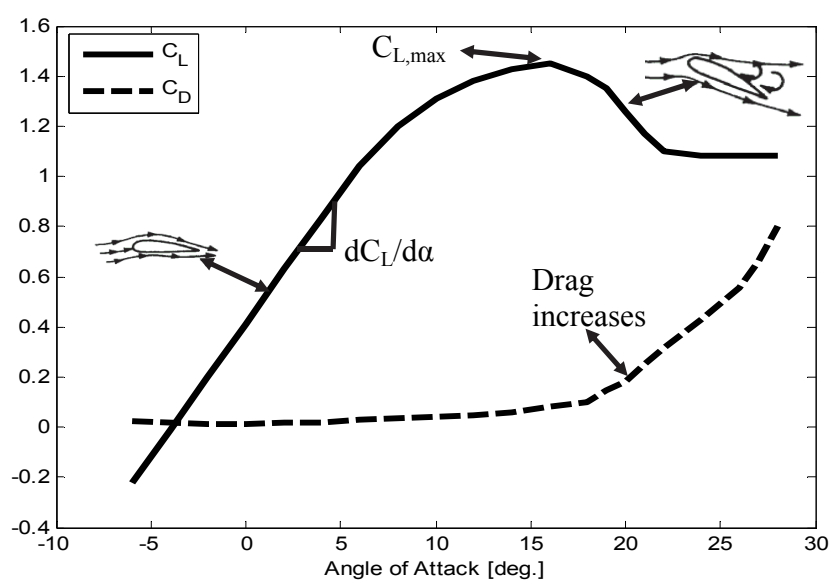

Figure 1. Lift and drag coefficients.

\subsection{Sources of uncertainty in airfoil data}

The static airfoil data in aero-servo-elastic software are not unique and exhibit variations which are driven by physical uncertainty or simply driven by lack of evidence (model, measurement and statistical uncertainty). A list of the sources of uncertainty are described in the following and supported by data from the literature or calculations done by the authors.

Wind tunnel measurements: The layout and geometry of a wind tunnel and test section, turbulence intensity, geometry and dimensions of the model airfoil, contraction ratio, maximum speed, Re number, Mach number, wind tunnel calibration, wake effects, lift and drag measurement technique (wind tunnel walls or airfoil itself), and the type of corrections applied to the test data are factors that contribute to the uncertainty in measuring airfoil lift and drag polar curves in wind tunnels (Bak et al. 2010). The lift curves shown in Figure 2 depict the same airfoil measured in 4 different wind tunnels at $\mathrm{Re}=3$ million. One can easily notice the variation in $\mathrm{C}_{\mathrm{L}, \max }$ and post stall characteristics as measured in the various wind tunnels. Based on this and other such measurements it can be shown that wind tunnel measurements uncertainty can result in a COV of the order of $6-9 \%$ on $C_{L, \max }, 3-9 \%$ on $A_{o} A_{\max }, 4-8 \%$ on $C_{L, S R}$ and $6 \%$ on $A_{0} A_{S R}, 5-6 \%$ on $C_{L, T E S}$ and $4-10 \%$ on AoA $A_{T E S}$. These values vary depending on the type of airfoil.

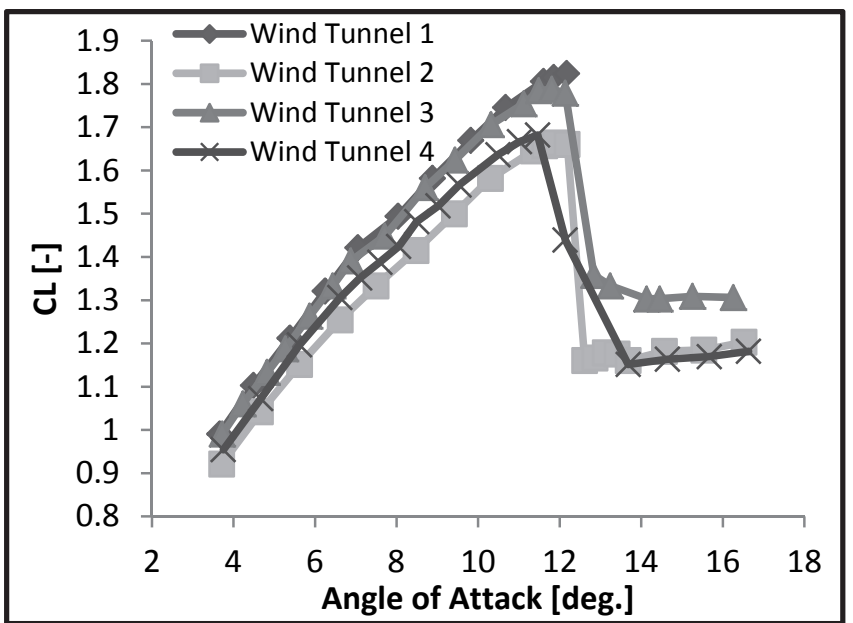

Figure 2. Lift coefficient for the same airfoil in 4 wind tunnels (ref. proprietary data).

3D rotational correction: Several empirical models exist to correct 2D wind tunnel measurements to include 3D effects on the lift coefficient and for some models also the drag coefficient. Models are developed by Bak et al., Snel et al., Du and Selig, Chaviaropoulos and Hansen, and Lindenburg (Bak et al. 2006). Figure 3 demonstrates the variation in $\mathrm{C}_{\mathrm{L}}$ on the NREL/NASA AEMS rotor. The designer's choice of the $3 \mathrm{D}$ correction model can result in large variations in the thrust level (Bak et al. 2006). The largest variation is observed near the root section. In the outer part of the blade, the choice of the $3 \mathrm{D}$ correction model can result in $6 \% \mathrm{COV}$ for $\mathrm{C}_{\mathrm{L}, \max }$, which becomes up to $14 \%$ close to the root of the blade.

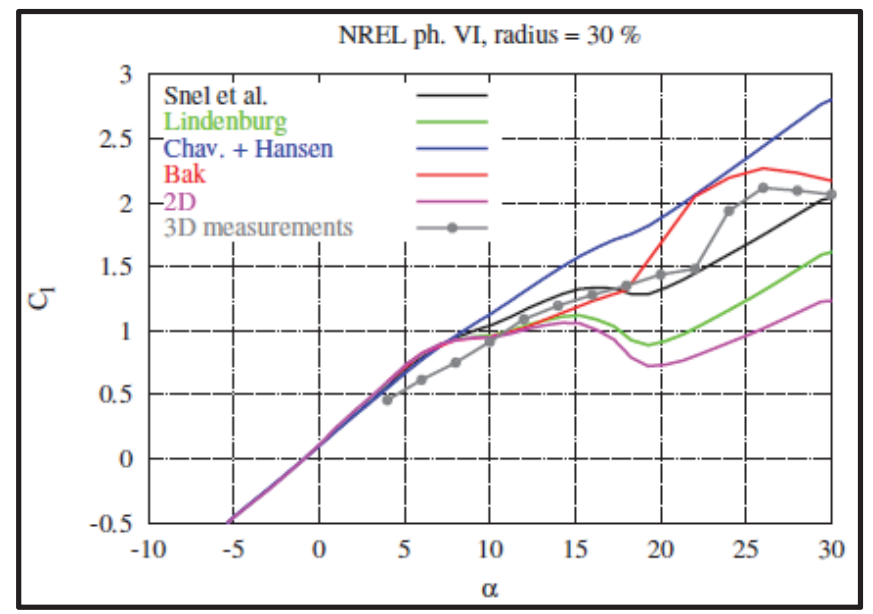

Figure 3. 3D corrected lift coefficient compared to measurements (Bak et al. 2006).

Surface roughness: The blades' surface conditions vary over a wind turbine's lifetime. The sur- 
face roughness variation is due to paint condition, surface finish, dust accretion, insects sticking to the surface and/or by erosion. Thus, leading edge roughness is simulated in wind tunnel tests. For any given section along the span of the blade a designer can choose to use clean, rough or mixed airfoil data. As shown in Figure 4, each has its own lift characteristics: A clean airfoil exhibits an abrupt stall and a higher max lift compared to a rough airfoil. Loads could be calculated with a clean airfoil while the turbine operates in rough conditions in the field or vice-versa. Consequently, it can be shown that roughness can result in a $\mathrm{COV}$ of the order of $3 \%$ on $\mathrm{C}_{\mathrm{L}, \max }, 4-6 \%$ on $\mathrm{AoA}_{\max }, 4 \%$ on $\mathrm{C}_{\mathrm{L}, \mathrm{SR}}$ and 6 $8 \%$ on $\mathrm{AoA}_{\mathrm{SR}}, 5-6 \% \mathrm{COV}$ on $\mathrm{C}_{\mathrm{L}, \mathrm{TES}}$ and $4-10 \%$ on $\mathrm{AoA}_{\mathrm{TES}}$. These numbers depend on the type of airfoil.

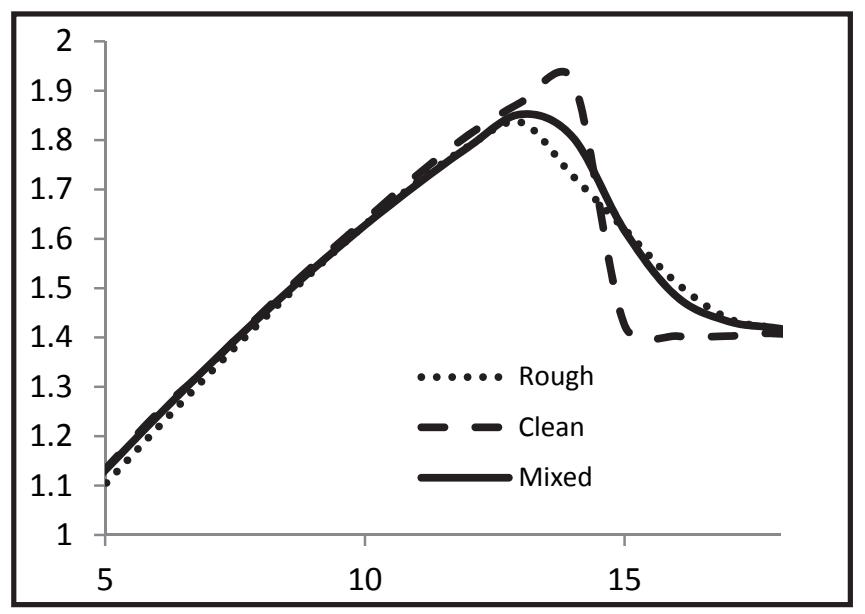

Figure $4 . \mathrm{C}_{\mathrm{L}}$ of an airfoil with 3 roughness conditions.

Geometric distortions of the blade during manufacturing and handling: The static $C_{L}$ and $C_{D}$ used by the designer are based on predefined geometry of the blade airfoils. However, manufacturing, handling, transportation and installation introduce geometric distortions to the blade sections, resulting in discrepancies between the design $C_{L}$ and $C_{D}$ and the "real" $C_{L}$ and $C_{D}$. Table 1 shows some of the distortions observed during manufacturing and handling. A combination of these distortions could occur anywhere along the span of the blade. Calculations done by the author where the geometric distortions are reproduced in a Monte Carlo scheme on a NACA 63418 and Risø B15 airfoils and $C_{L}$ and $C_{D}$ are computed in XFOIL (Drela 1989) up to $\mathrm{C}_{\mathrm{L}, \max }$ show a COV of the order of $2-3 \%$ on $\mathrm{C}_{\mathrm{L}, \max }$ and the difference between the min and max observed $C_{L \text {,max }}$ is of the order of $12 \%$. In the Monte Carlo scheme all geometric distortions are assigned specific distributions and are assumed to be fully uncorrelated.

Reynolds number Correction: The Re number varies along the span of the blade but the wind tunnel measurements are usually performed at a limited range of Re numbers; the static airfoil data are then corrected to the actual Re number for each section along the span of the blade (Yamauchi et al. 1983). Figure 5 demonstrates the variation of lift as a function of the Re number (Ceyhan 2012). With increasing rotor diameters, the operating Re numbers are expected to rise above 20 million and few wind tunnels exist to perform measurement at such high values. Consequently, increased reliance on numeric Re corrections is expected (i.e. RFoil or CFD). Based on this and other such measurements (Yoshida et al. 2000) it can be shown that Re effects can result in a $\mathrm{COV}$ of the order of $6 \%$ on $\mathrm{C}_{\mathrm{L} \text {,max }}, 8 \%$ on AoA max, $4 \%$ on $\mathrm{C}_{\mathrm{L}, \mathrm{SR}}$ and $15 \%$ on $\mathrm{AoA}_{\mathrm{SR}}, 13 \%$ on $\mathrm{C}_{\mathrm{L}, \mathrm{TES}}$ and $8 \%$ on AoA $\mathrm{A}_{\mathrm{TES}}$. These numbers depend on the type of airfoil, roughness conditions and Mach number.

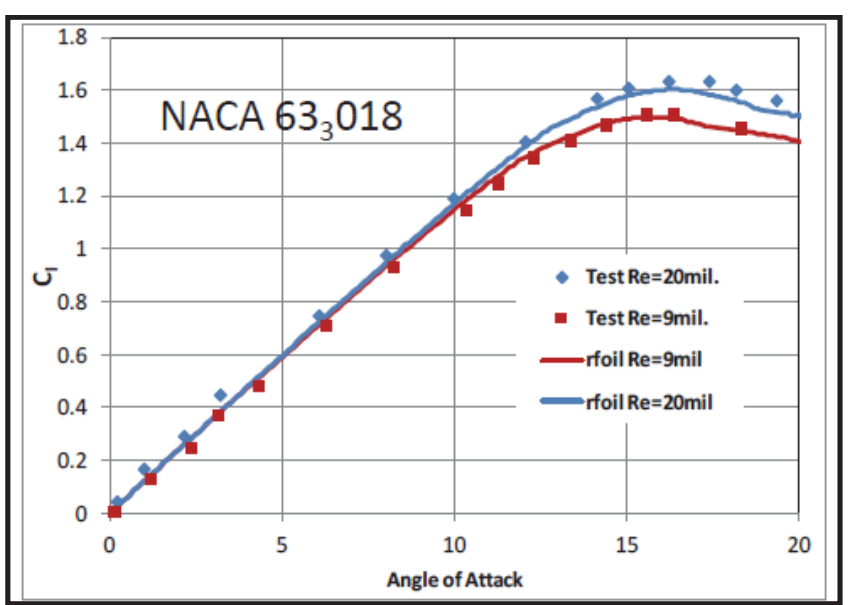

Figure 5. Variation of lift with Re number in both wind tunnel test and numerical calculations (Ceyhan et al. 2012).

Table 1. Observed geometric distortions in manufacturing.

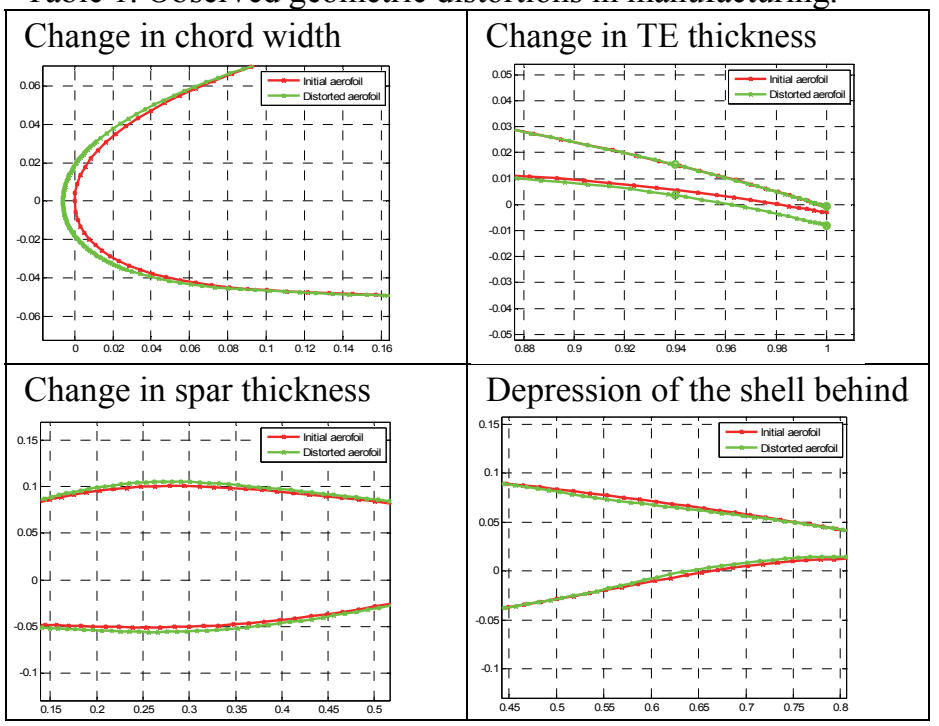

Geometric distortions of the blade under loading: the blade geometry deforms due to aerodynamic and inertial loading, centrifugal stiffening, and gravitational effects, resulting in discrepancy between the static $C_{L}$ and $C_{D}$ in the aero-elastic model and the "real" $C_{L}$ and $C_{D}$ for the deformed 
blade. Loeven et al. (2008) treats airfoil geometry as uncertain with normally varying camber, camber position and thickness to chord ratio $(\mathrm{COV}=10 \%)$ using a probabilistic collocation approach. This approach assumes that the three parameters are enough to simulate geometric distortions due to manufacturing tolerances, aerodynamic loading, icing and wear. The result is a $4-6 \% \mathrm{COV}$ on $\mathrm{C}_{\mathrm{L}, \max }$.

Extending airfoil data to post stall: The angles of attack on a wind turbine blade range from -180 to +180 degrees depending on the operating conditions and external inflow. Wind tunnel measurements are available for a limited range of angles of attack. Empirical models such as the Viterna method (Viterna et al. 1981) or Eggleston and Stoddard (Eggleston et al. 1987) have been suggested to extend the airfoil data to post stall. Results presented by Tangler et al. (2005) indicate that the Viterna method in post stall and deep stall is highly sensitive to the available wind tunnel measured $\mathrm{C}_{\mathrm{L}}$ and $\mathrm{C}_{\mathrm{D}}$. $\mathrm{A}$ change of $10 \%$ in $\mathrm{C}_{\mathrm{L}}$ and $\mathrm{C}_{\mathrm{D}}$ results in $5 \%$ change in power at $25 \mathrm{~m} / \mathrm{s}$ (thrust follows a similar trend).

Validation of airfoil data by full scale measurements: Within the wind industry it is common to validate the static wind tunnel $C_{L}$ and $C_{D}$ data used in the aero-elastic model by comparing the computed power curve to a measured power curve on a select number of wind turbine prototypes. The $\mathrm{C}_{\mathrm{L}}$ and $\mathrm{C}_{\mathrm{D}}$ are "adjusted" such that the simulated power curve fits the measured power curve (similarly for mean flapwise bending moment). The "adjusted" $C_{L}$ and $C_{D}$ are then adopted in the design of future rotors. It is evident that this process is only valid for a specific wind turbine on site specific conditions. Future turbines are not identical to the prototypes nor are the sites conditions, and thus the adjusted $C_{L}$ and $C_{D}$ will no longer be valid.

\subsection{Categorizing uncertainties}

Aleatory uncertainties represent inherent natural variability and cannot be reduced. Epistemic uncertainties (model, measurement and statistical) are due to the lack of knowledge and can be reduced by collecting more data. These sources of uncertainties are categorized in Table 2 to allow for the optimization of resource allocations to reduce the overall uncertainty of the airfoil data.

Table 2. epistemic and aleatory uncertainties.

\begin{tabular}{l|l}
\hline Epistemic uncertainties & Aleatory uncertainties \\
\hline Wind tunnel, Re corrections, 3D & Surface roughness, \\
corrections, Extending airfoil data & Geometric distortions of \\
to post stall, Validation of airfoil & the blade under loading, \\
data by full scale measurement, & Wind tunnel, Validation \\
Geometric distortion of the blade & of airfoil data by full \\
during manufacturing and handling & scale measurement \\
\hline
\end{tabular}

\subsection{Parameterization of the lift coefficient curve}

The above uncertainties are sources of variations of the lift and drag coefficients, which occur on the rotor blades during the life time of the wind turbine. Hence the objective is to be able to reproduce these physical variations already at the design stage in order to take their effect on extreme loads effects (and in principle for fatigue loads as well). To do so in a relatively simple way, it is deemed necessary to parameterize the lift and drag polar curves. At low angles of attack, the lift coefficient is parameterized by the slope in the linear range $\mathrm{dC}_{\mathrm{L}} / \mathrm{d} \alpha$ (dashed line in Figure 6), the point indicating the start of $\mathrm{TE}$ separation $\left(\mathrm{T}_{\mathrm{ES}}\right)$, the point of max lift $\left(\mathrm{C}_{\mathrm{L}, \max }\right)$ and the point where stall recovery is initiated $\left(S_{R}\right)$. The rate of change of the lift coefficient with angle of attack $\left(\mathrm{dC}_{\mathrm{L}} / \mathrm{d} \alpha\right)$ can be inferred from thin airfoil theory. On any given airfoil section and $\mathrm{C}_{\mathrm{L}}$ curve, $\mathrm{dC}_{\mathrm{L}} / \mathrm{d} \alpha$ is parameterized as $2 \pi+/-10 \% . \mathrm{T}_{\mathrm{ES}}$ is chosen when $\mathrm{dC}_{\mathrm{L}} / \mathrm{d} \alpha$ drops strictly below $2 \pi-10 \%$ indicating a shift from attached flow in the linear region of the lift curve and the start of trailing edge separation. $\mathrm{C}_{\mathrm{L}, \max }$ is chosen where the lift reaches a maximum value after the start of TE separation $\left(\mathrm{dC}_{\mathrm{L}} / \mathrm{d} \alpha=0\right)$. Beyond $\mathrm{C}_{\mathrm{L}, \max }$, the lift coefficient starts to decrease. Deep stall $\left(\mathrm{S}_{\mathrm{R}}\right)$ is obtained when the separated flow reaches the trailing edge; Mathematically $S_{R}$ is chosen when the $\mathrm{d}^{2} \mathrm{C}_{\mathrm{L}} / \mathrm{d} \alpha^{2}$ changes sign from negative to positive. For high angles of attack the parameterization is performed as follows: at $90 \mathrm{deg}$. AoA, an airfoil resembles a flat plat and exhibits $C_{L}$ values approaching zero (depending on camber, thickness and LE radius). The parameterization is thus done by linearly reducing the $\mathrm{C}_{\mathrm{L}}$ between $\mathrm{S}_{\mathrm{R}}$ and $C_{L, 90}$. Similarly, the $C_{L}$ between 90-150 deg. AoA is linearly increased.

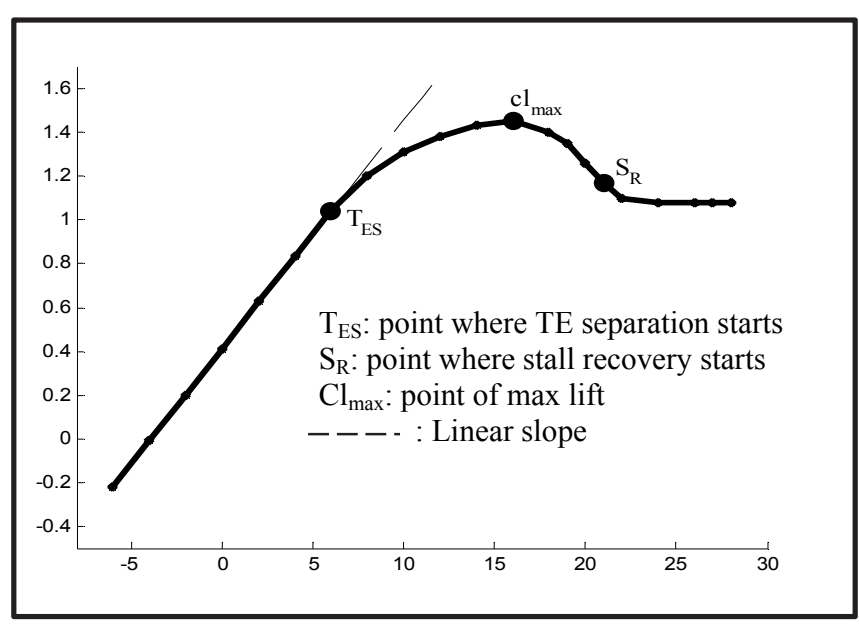

Figure 6. Parameterization of $\mathrm{C}_{\mathrm{L}}$ for low angles of attack.

\subsection{Parameterization of the drag coefficient curve}

The drag coefficient is several orders of magnitudes smaller than the lift coefficient for small angles of attack (below stall) and its impact on extreme loads 
is limited. Up to 30deg. angle of attack, the $C_{D}$ displays minor change regardless of the airfoil type, geometry, or thickness to chord ratio (Timmer 2010). Consequently, the drag coefficient is only parameterized by the point where max drag coefficient occurs at +/-90deg. angle of attack where it exhibits the largest variations.

\subsection{Stochastic model parameters}

The stochastic variables are defined in Table 3 by their distribution, expected value and the coefficient of variation.

Table 3. Stochastic variables

\begin{tabular}{lccc}
\hline Variable & Distribution & $\begin{array}{l}\text { Expected } \\
\text { value }\end{array}$ & COV \\
\hline $\mathrm{dC}_{\mathrm{L}} / \mathrm{d} \alpha$ & $\mathrm{N}$ (truncated) & $0.1096 / \mathrm{deg}$ & $0.033^{*}$ \\
\hline $\mathbf{C}_{\mathbf{L}, \mathbf{m a x}}$ & $\mathrm{N}$ (truncated) & $\mu$ & 0.12 \\
\hline $\mathbf{A o} \mathbf{A}_{\mathbf{m a x}}$ & $\mathrm{N}$ (truncated) & $\mu$ & 0.08 \\
\hline $\mathbf{C}_{\mathbf{L}, \mathbf{T E S}}$ & $\mathrm{N}$ (truncated) & $\mu$ & 0.13 \\
\hline $\mathbf{A o A}_{\mathbf{T E S}}$ & $\mathrm{N}$ (truncated) & $\mu$ & 0.10 \\
\hline $\mathbf{C}_{\mathbf{L}, \mathbf{S R}}$ & $\mathrm{N}$ (truncated) & $\mu$ & 0.08 \\
\hline $\mathbf{A o A}_{\mathbf{S R}}$ & $\mathrm{N}$ (truncated) & $\mu$ & 0.15 \\
\hline $\mathbf{C}_{\mathbf{D , 9 0}}$ & $\mathrm{N}$ (truncated) & $\mu$ & 0.10 \\
\hline 0.1096
\end{tabular}

${ }^{*} 0.1096 / \mathrm{deg}+/-10 \%$ is assumed to lie within $+/-3$ sigma

Based on more than $26 \mathrm{C}_{\mathrm{L}}$ curves measured in multiple wind tunnels, Re, roughness conditions, and geometric distortions on various types of airfoils there seems to be a trend indicating correlations which are estimated to be:

\begin{tabular}{|c|c|c|c|c|c|c|}
\cline { 2 - 7 } \multicolumn{1}{c|}{} & $\mathrm{C}_{\mathrm{L}, \max }$ & $\mathrm{C}_{\mathrm{L}, \mathrm{SR}}$ & $\mathrm{C}_{\mathrm{L}, \mathrm{TES}}$ & AoA $_{\max }$ & AoA $_{\mathrm{SR}}$ & AoA $_{\mathrm{TES}}$ \\
\hline $\mathrm{C}_{\mathrm{L}, \max }$ & 1.00 & 0.86 & 0.49 & 0.18 & 0.02 & -0.25 \\
\hline $\mathrm{C}_{\mathrm{L}, \mathrm{SR}}$ & 0.86 & 1.00 & 0.31 & -0.29 & -0.34 & -0.36 \\
\hline $\mathrm{C}_{\mathrm{L}, \mathrm{TES}}$ & 0.49 & 0.31 & 1.00 & 0.50 & 0.49 & -0.59 \\
\hline $\mathrm{AoA}_{\max }$ & 0.18 & -0.29 & 0.50 & 1.00 & 0.88 & 0.21 \\
\hline $\mathrm{AoA}_{\mathrm{SR}}$ & 0.02 & -0.34 & 0.49 & 0.88 & 1.00 & 0.30 \\
\hline $\mathrm{AoA}$ & -0.25 & -0.36 & -0.59 & 0.21 & 0.30 & 1.00 \\
\hline
\end{tabular}

\subsection{Results of parameterization}

Figure 7 represents a sample reproduction of $C_{L}$ and $C_{D}$ curves based on the parameterization method. Below is a brief verification guideline which is used to ensure that the synthetic (generated) lift and drag curves are physical:

- $\mathrm{C}_{\mathrm{L}} / \mathrm{C}_{\mathrm{D}} \sim 0$ at $\mathrm{AoA}=90^{\circ}$ and $\mathrm{C}_{\mathrm{L}} / \mathrm{C}_{\mathrm{D}} \sim 1$ at $\mathrm{AoA}=45^{\circ}$

- Comparable $\mathrm{C}_{\mathrm{L}} / \mathrm{C}_{\mathrm{D}}$ from $\alpha=30^{\circ}$ to $\alpha=90^{\circ}$

It should be noted that this paper does not consider other uncertainties such as model uncertainty on the simulated Extreme Turbulence or Extreme Wind, nor dynamic stall and dynamic wake.
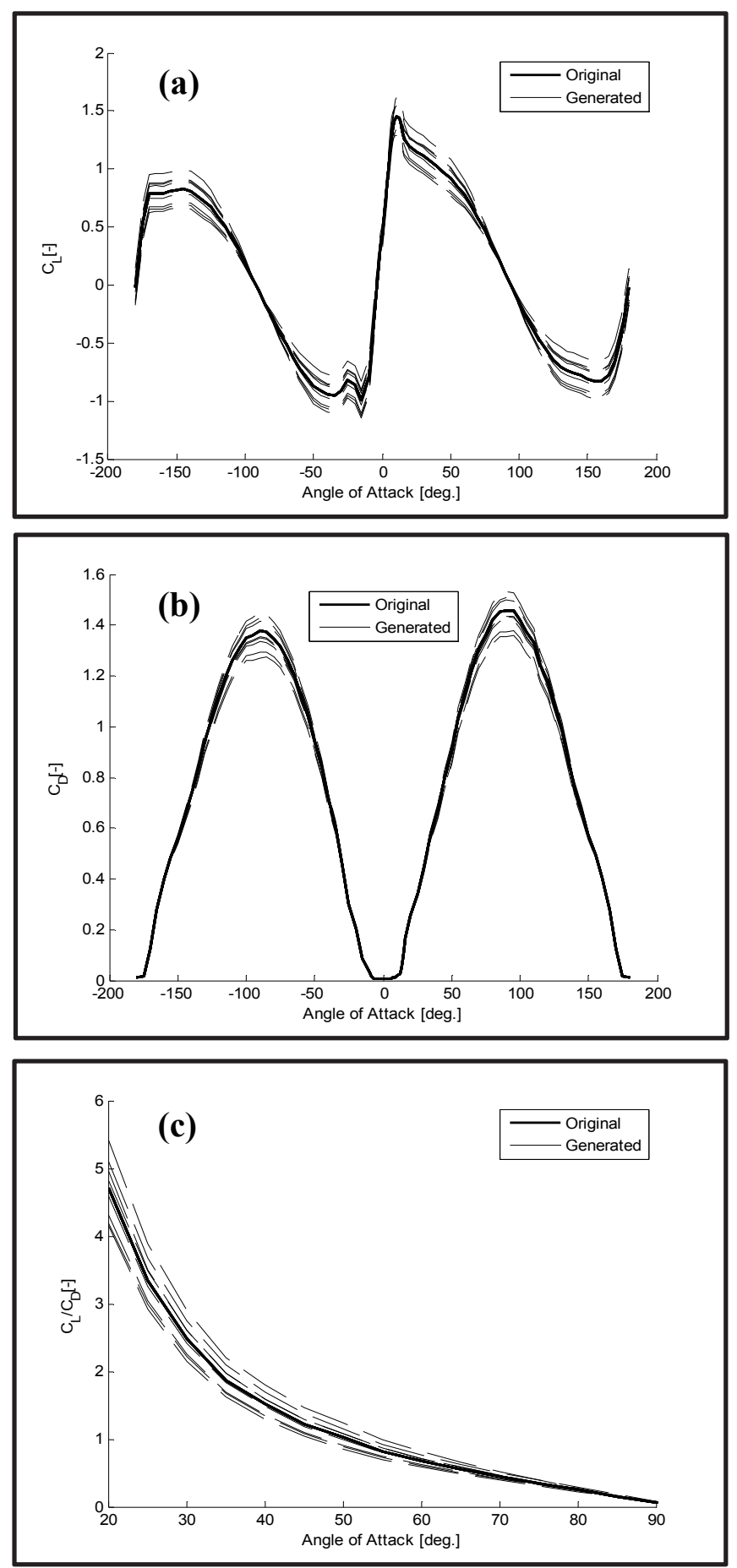

Figure 7. Generated (a) lift, (b) drag and (c) lift to drag ratio.

\section{TURBINE LOADS EFFECTS}

\subsection{The Aero-servo-elastic software}

The aero-servo-elastic calculations are performed in FAST (Jonkman 2005) with a custom PID controller for the turbine. This version of FAST allows up to 24 DOFs. These DOFs include two blade-flap modes and one uncoupled blade-edge mode per blade. It also has two fore-aft and two side-to-side tower bending modes in addition to nacelle yaw. The next DOF is for the generator azimuth angle, and another DOF is the compliance in the drivetrain between the generator and hub/rotor. A limited number of design governing extreme load cases are used in this study which are DLC1.3 Extreme Turbulence 
Model and DLC6.2 Extreme Wind Model (IEC61400-1 2005). The load cases are only run at wind speeds where the load is known to reach peak values as shown in Table 4 (61400-1 2005). Other IEC61400-1 load cases such as extreme coherent gusts and shear gusts, wind direction changes combined with control faults are also critical design driving load cases for large offshore wind turbines but are not considered here for their complex probabilistic nature.

Table 4. Load cases from IEC61400-1 (2005).

\begin{tabular}{ll}
\hline Load case & $\begin{array}{l}\text { Simulated mean wind speed and } \\
\text { yaw error }\end{array}$ \\
\hline DLC 1.3 ETM & Vrat $^{*}, 0$ deg. yaw error \\
DLC 6.2 EWM & IEC1 Vref ${ }^{* *},+30$ deg. yaw error
\end{tabular}

${ }^{*}$ Vrat is the rated mean wind speed. ${ }^{* *}$ Vref is the reference wind speed averaged over $10 \mathrm{~min}(50 \mathrm{~m} / \mathrm{s}$ for class IEC1).

Twenty four simulations (10-minunte stochastic realizations) are carried out at $\mathrm{V}_{\text {rat }}$ for DLC1.3ETM and $\mathrm{V}_{\text {ref }}$ for DLC6.2EWM at +30 degree yaw error which is generally a critical wind direction for loads effects for long and slender blades. One thousand static airfoil data are generated in a Monte Carlo scheme based on the parameterization method described in section 2; from these, twenty six are randomly selected to estimate the extreme loads effects (COV converges after twenty five). Table 5 shows the total number of simulations per design load case. For each 600 s simulation the global extreme load effect is extracted; in total $24 \times 26$ extreme values are extracted for each design load case (Peak over Threshold or other extreme value methods are not applied in this paper).

Table 5. Loads effects simulations.

\begin{tabular}{lccll}
\hline DLC & $\begin{array}{l}\mathrm{V} \\
{[\mathrm{m} / \mathrm{s}]}\end{array}$ & $\begin{array}{l}\text { Stochastic } \\
\text { realizations } \\
\text { per wind } \\
\text { speed }\end{array}$ & $\begin{array}{l}\text { Monte } \\
\text { Carlo } \\
\text { Generated } \\
\text { airfoil data }\end{array}$ & $\begin{array}{l}\text { Total } \\
\text { number of } \\
\text { simulations }\end{array}$ \\
\hline 1.3ETM & Vrat & 24 & 26 & 624 \\
\hline 6.2EWM & Vref & 24 & 26 & 624 \\
\hline
\end{tabular}

The extreme loads effects are estimated for the 'sensors' shown in Table 6. The notation 'sensors' is used because these loads effects are measured by strain gauges on wind turbines.

Table 6. Simulated load output sensors.

\begin{tabular}{lll}
\hline Component & Load causing failure & Location \\
\hline Blade & $\begin{array}{l}\text { Flap and edge bending mo- } \\
\text { ments }\end{array}$ & $\begin{array}{l}\text { Blade root } \\
3 / 4 \text { span }\end{array}$ \\
& Out of plane tip deflection & \\
\hline $\begin{array}{l}\text { Machine } \\
\text { frame }\end{array}$ & $\begin{array}{l}\text { Driving, tilt and yaw mo- } \\
\text { ments }\end{array}$ & Main bearing \\
\hline Tower & Fore-aft bending moment & $\begin{array}{l}\text { Tower base } \\
3 / 4 \text { hub height }\end{array}$ \\
\hline
\end{tabular}

\subsection{Effect of aerodynamic uncertainty on extreme loads}

Figure 8 shows ten density functions of the normalized blade root extreme flap bending moment for DLC1.3ETM and DLC6.2EWM, respectively. Each density function corresponds to an airfoil data. $\mathrm{Ob}-$ serving the modes of the density functions one can clearly confirm that variations in airfoil data have a direct effect on extreme loads effects. The total COV on the 50-year load effect is calculated in Table 7.
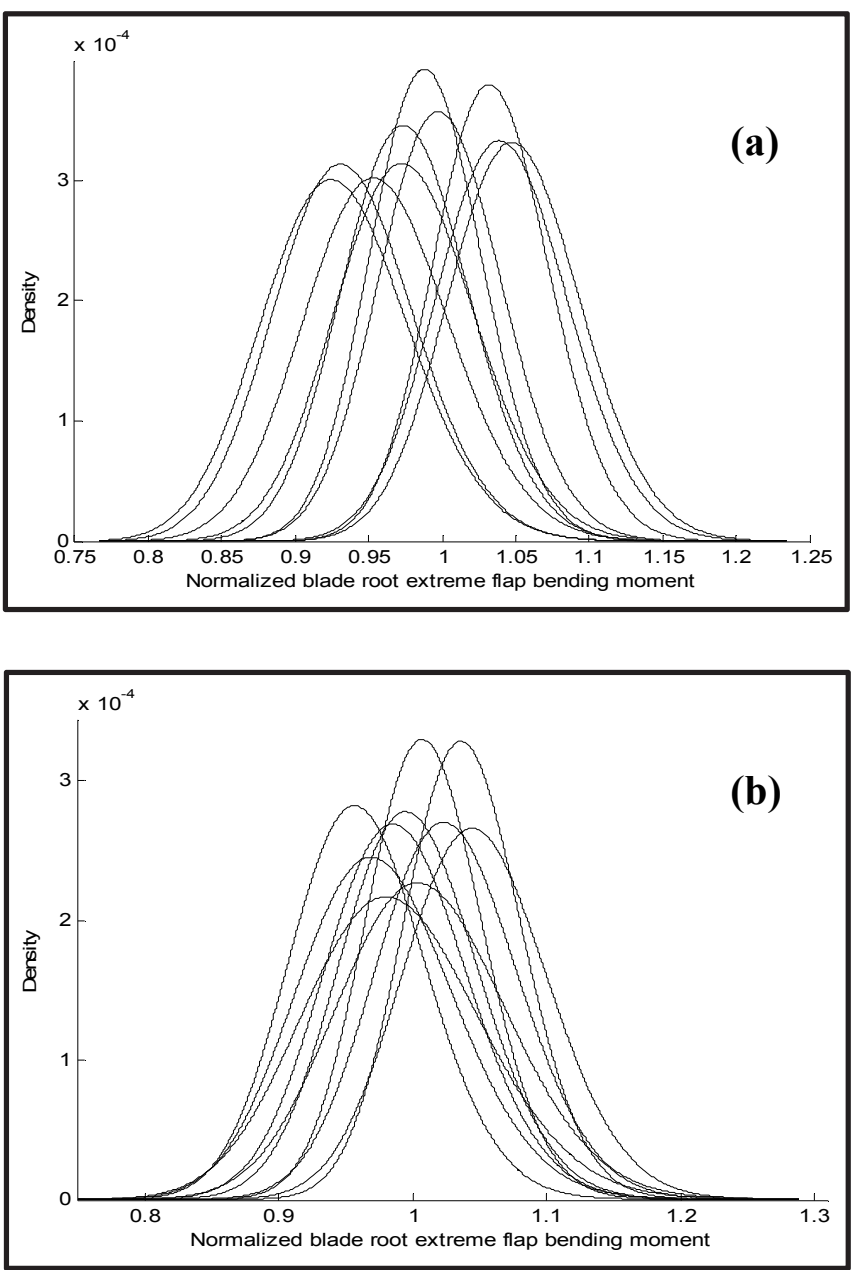

Figure 8. Ten airfoil data are generated and the corresponding density functions of the normalized blade root extreme flap bending moment for (a) DLC1.3ETM and (b) DLC6.2EWM are plotted.

Table 7. COV for extreme load effects in DLC1.3 and DLC6.2.

\begin{tabular}{lllll}
\hline $\begin{array}{l}\text { Com- } \\
\text { ponent }\end{array}$ & Sensor & $\begin{array}{l}\text { Loca- } \\
\text { tion }\end{array}$ & $\begin{array}{l}\text { COV } \\
\text { DLC } \\
1.3\end{array}$ & $\begin{array}{l}\text { COV } \\
\text { DLC } \\
6.2\end{array}$ \\
\hline Blade & Edgewise bending moment & root & 0.017 & 0.060 \\
& Edgewise bending moment & $3 / 4$ span & 0.035 & 0.085 \\
& Flapwise bending moment & root & 0.042 & 0.038 \\
& Flapwise bending moment & $3 / 4$ span & 0.060 & 0.045 \\
& Out of plane tip deflection & tip & 0.054 & 0.058 \\
\hline Ma- & Driving moment & Main & 0.009 & 0.047 \\
chine & Tilt moment & bearing & 0.070 & 0.099 \\
frame & Yaw moment & & 0.056 & 0.029 \\
\hline Tower & Fore-aft bending moment & base & 0.040 & 0.018 \\
& Fore-aft bending moment & $3 / 4 \mathrm{H}$ & 0.046 & 0.020 \\
\hline & & & &
\end{tabular}




\subsection{Spanwise correlation of airfoil data}

So far it has been tacitly assumed that the seven adjacent aerodynamic sections on the blade are independent. This is not a very reasonable assumption as adjacent locations may well be correlated. the correlation of airfoil data along the span of the blade is now considered. For this, the "correlation length" needs to be derived, which is not straightforward but is examined as per the following details:

- Radial flow in the root has reaching effects up to $20-30 \%$ of the blade length.

- Depending on the blade geometry and operating RPM, the Re number is constant (within $+/-5 \%$ ) between $30 \%-60 \%$ of the blade length. Near the root and the tip of the blade the Re exhibits steep change.

- On most large blades, the outer $20-30 \%$ of the blade is covered by the same airfoil family of similar $\mathrm{t} / \mathrm{c}$ ratio and the flow can be considered 2 -dimensional. From there the $\mathrm{t} / \mathrm{c}$ starts to increase rapidly for structural reasons.

- Some geometric distortions due to manufacturing and handling can affect a length up to $15 \%$ of the blade length in the worst case. The affected area is larger when geometric distortion of the blade is due to loading (deflection).

- The effect on induction from changing the lift and drag characteristics in the blade tip is studied in a static BEM at rated wind speed and rated RPM. The results shown in Figure 9 indicate an affected length up to $15 \%$ from the blade tip.

Consequently it can be concluded that a reasonable correlation length for all stochastic variables is of the order of $20 \%$ of the blade length.

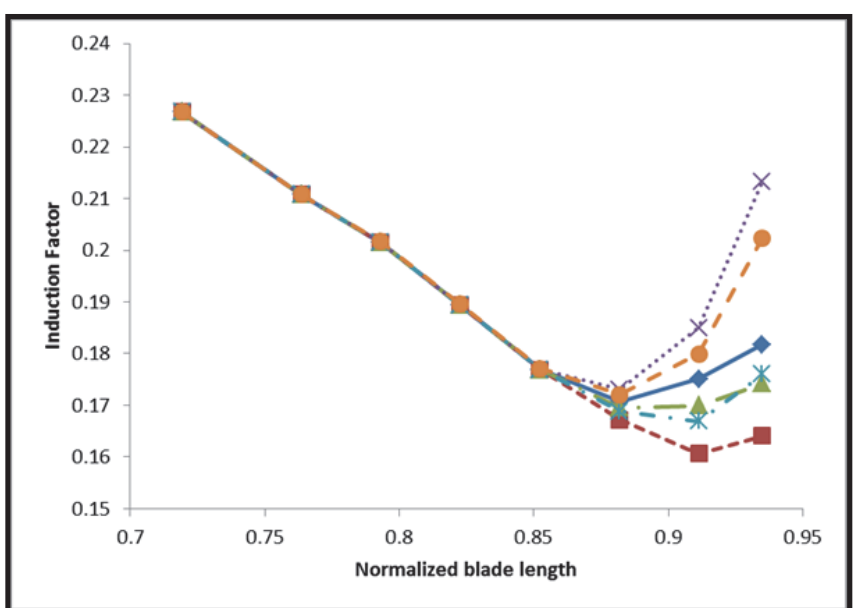

Figure 9. Six perturbations of airfoil data are generated in the tip section of the blade and the induction factor is calculated along the span of the blade. The affected length is of the order of $15 \%$ of the blade length from the tip.

The blade sections are assumed correlated using an Exponential correlation function with a correlation length equivalent to $20 \%$ of the blade length:

$c(r)=\exp \left(-r / r_{0}\right)$
Where $r$ is a radial location along the span of the blade ranging from 0 to $\mathrm{R}$ where $\mathrm{R}$ is the blade length and $r_{0}$ is the correlation length $\left(r_{0}=20 \%\right.$ of the blade length). The fully correlated airfoil stochastic parameters along the span of the blade are generated as:

$X=\mu+\sigma T U$

where $\boldsymbol{U}$ is a vector of standard normal stochastic variables, $\boldsymbol{T}$ is a lower triangular matrix of the Cholesky decomposition of the correlation matrix, $\boldsymbol{\mu}$ is a vector of the mean values and $\boldsymbol{\sigma}$ is a diagonal matrix containing the standard deviations of the stochastic parameters. The diagonal blocks of the correlation matrix are the correlations amongst the stochastic variables in one blade section (see 2.5); the off-diagonal elements are the correlation coefficients from one section to another along the span of the blade generated by Equation 1 .

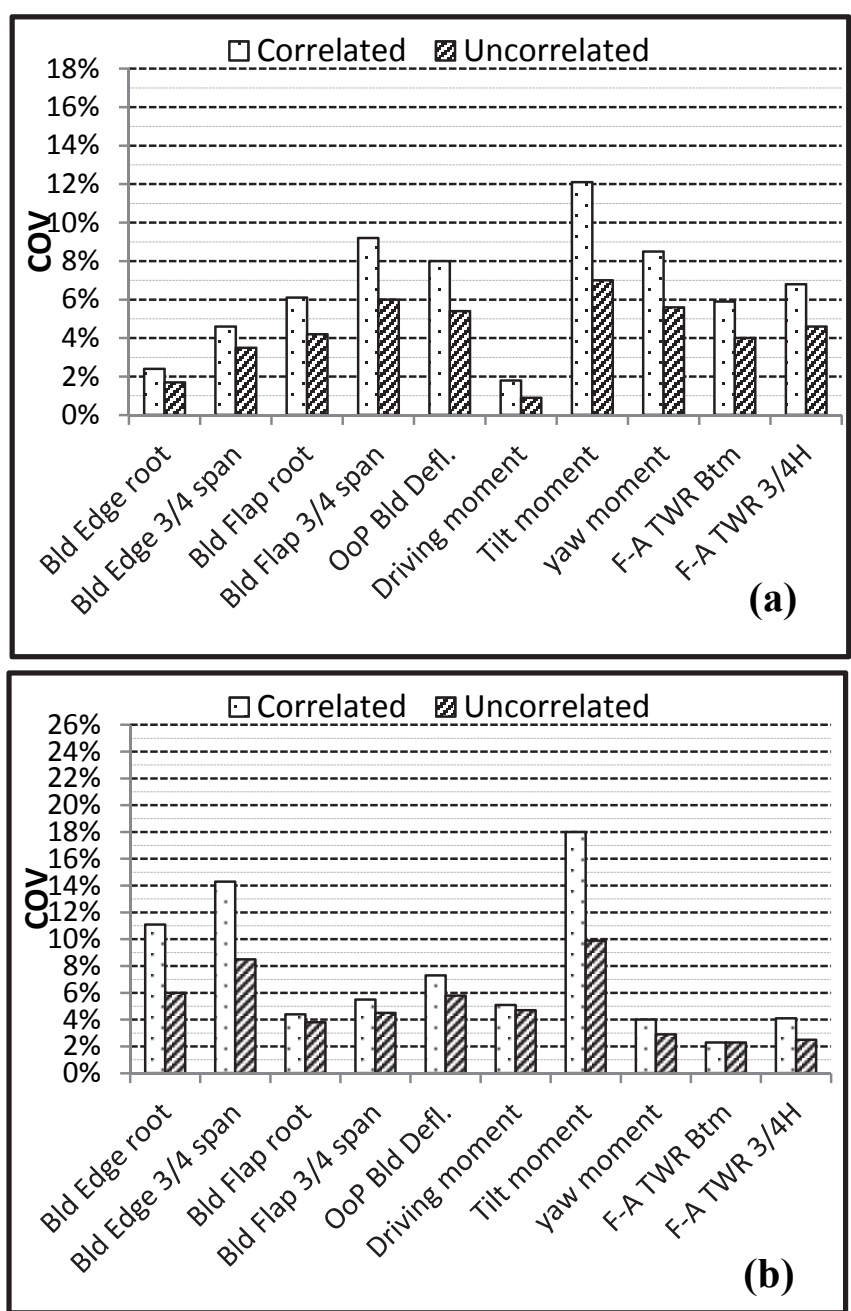

Figure 10. COV for extreme load effects in (a) DLC1.3 and (b) DLC6.2 when the airfoil data correlation along the span of the blade is included.

Figures 10 shows the COV of the 50 year extreme loads effects for both correlated and uncorrelated static airfoil data (statistical uncertainties on the 
COV are not considered here). The results reveal several interesting trends:

- There is a clear trend indicating as expected an increase in the COV of the extreme load effects in both DLC1.3ETM and 6.2EWM when the airfoil data are correlated.

- The extreme tilt bending moments exhibits the largest $\mathrm{COV}$ indicating that asymmetric loads are the most sensitive to uncertainty in airfoil data. A control system targeting asymmetric loads can potentially reduce this effect.

- The edgewise extreme bending moment and main shaft driving moment are the least affected by the uncertainty in airfoil data in operating conditions in DLC1.3.

- Except for the edgewise extreme bending moment and main shaft extreme tilt moment, the extreme loads effects are largely insensitive to the uncertainty in airfoil data in DLC6.2.

- The flapwise and edgewise extreme bending moments near the blade tip exhibit larger sensitivity towards uncertainty in airfoil data compared to the blade root in operating conditions.

- The COV of the extreme edgewise bending moments in DLC6.2EWM is significantly larger when the airfoil data are correlated. This is an interesting observation indicating that a decoupling of blade sections aerodynamically can potentially reduce edgewise loads in stand-still which is a significant problem for large and slender blades. The same can be concluded for the extreme tilt moment.

\section{CONCLUSIONS}

In this paper a stochastic model of the static airfoil data is proposed including correlations amongst the stochastic parameters along the span of the blade. The stochastic model is developed using a Monte Carlo scheme to replicate the uncertainties in airfoil data by parameterizing the lift and drag polar curves. The results indicate that uncertainty in static airfoil data results in a coefficient of variation up to $9 \%$ in the blade flap and $14 \%$ in the edgewise extreme bending moments (in standstill EWM), $7 \%$ in the tower for-aft extreme bending moment and $18 \%$ in the extreme tilt moment (in standstill EWM) and 9\% in the extreme yaw moment. There is a clear trend indicating an increase in the coefficient of variation of the extreme load effects in both DLC1.3ETM and 6.2EWM when the airfoil data are correlated along the span of the blade. Having quantified the effect of uncertainty of aerodynamic airfoil data on extreme loads, future studies can utilize these results to optimize the loads partial safety factors (Tarp-Johansen et al. 2002) in the context of a wind turbine under the influence of an advanced control system.

\section{REFERENCES}

Bak, C., Johansen, J., Andersen, P.B. 2006. Three-dimensional corrections of airfoil characteristics based on pressure distributions (paper and poster). In: Proceedings (online). Brussels : European Wind Energy Association, 2006.

Bak, C., et al. 2010. DAN-AERO MW: Comparisons of airfoil characteristics for two airfoils tested in three different wind tunnels. In: Torque 2010: The science of making torque from wind. EWEA, 2010: 59-70.

Ceyhan, O. 2012. High Reynolds number effects on 20MW wind turbine rotor design. The science of making torque from wind conference, 9-11 October 2012, Oldenburg.

Drela, M. 1989. XFOIL: An analysis and design system for low Reynolds number airfoils. Lecture Notes in Engineering, vol. 54. Low Reynolds Number Aerodynamics. Springer-Verlag, New York.

Eggleston D.M., Stoddard F.S. 1987. Wind Turbine Engineering Design. Van Nostrand Reinhold Co. Inc., New York, N.Y. 1987

IEC61400-1:2005 (ed. 3): Wind turbines - Part 1: Design Requirements.

Jonkman, J. M.; Buhl Jr., M. L. 2005. FAST User's Guide. NREL/EL-500-29798. Golden, Colorado: National Renewable Energy Laboratory, 2005.

Loeven, G.J.A., Bijl, H. 2008. Airfoil analysis with uncertain geometry using the probabilistic collocation method. AIAA 2008-2070

McCroskey W.J. 1987. A critical assessment of wind tunnel results for the NACA 0012 airfoil. NASA technical Memorandum 100019 USAAVSCOM Technical Report 87-A-5.

Ostowari C., Naik D. 1985. Post Stall studies of untwisted varying aspect ratio blades with an NACA 4415 airfoil section Part 2. Wind Engineering, vol. 9, No. 3.

Petrone G., De Nicola C., Quagliarella D., Witteveen J., Iaccarino G. 2011. Wind turbine performance analysis under uncertainty. AIAA 2011-544.

Simms D., Schreck S., Fingersh L.J. 2001. NREL Unsteady Aerodynamics Experiment in the NASA-Ames Wind Tunnel: A Comparison of Predictions to Measurements. NREL/TP-500-29494.

Tangler J., Kocurek J. 2005. Wind Turbine Post Stall Airfoil performance Characteristics Guidelines for Blade Element Momentum Methods. 43rd AIAA Aerospace SciencesMeeting and Exhibit, Reno, Nevada.

Tarp-Johansen N.J., Madsen P., Frandsen S. 2002. Partial Safety Factors for Extreme Load Effects. Risø-R-1319.

Timmer W.A., 2010. Aerodynamic characteristics of wind turbine blade airfoils at high angles-of-attack. In: Torque 2010: The science of making torque from wind. EWEA.

Viterna L., Corrigan R. 1981. Fixed pitch rotor performance of large horizontal axis wind turbines. NASA Lewis Research Center, N83 19233. DOE/NASA Workshop on Large Horizontal Axis Wind Turbines, Cleveland, July 1981.

Witteveen J.A.S., Doostan A., Pecnik R., Iaccarino G. 2009. Uncertainty quantification of the transonic flow around the RAE 2822 airfoil. Center for turbulence research, Annual Research Brief 2009. Stanford University.

Yamauchi G., Johnson W. 1983. Trends of Reynolds Number Effects on two-dimensional airfoil characteristics for helicopter rotor analysis. NASA Technical Memorandum 84363 N83-24472.

Yoshida K., Nogushi M. 2000. Adverse Reynolds number effects on maximum lift of two dimensional airfoils. ICAS 2000 Congress. 